\title{
THE PREMISES CREATED BY THE INFORMATION SOCIETY FOR THE USE OF THE INFORMATION TECHNOLOGY AND COMMUNICATIONS IN THE EXTERNAL AUDIT
}

\author{
Ph.D. Vasile Dumitras, “Valahia” University, Târgoviste
}

\section{SYNOPSIS}

The transition to the Information Society is one of the strategic objectives of the Romanian government for the period 2004-2008.

The Information Society, through which the frame for crossing to the economy and the society based on knowledge is created, assumes and trains changes of paradigm in all areas, for instance: in administration through e-government, $e$-administration systems, in business through on-line commerce, in education through distance education, in culture through multimedia centers and virtual libraries and even in the actual manner of working with support systems for work at distance.

The generalization of the implementation and use of these types of systems for the entire public administration will entrain qualitative substance changes of the external audit approach.

\section{Concise presentation of the current status of the scientific research work}

The transition to the Information Society is one of the strategic objectives of the Romanian government for the period 2004-2008.

The Information Society, through which the frame for crossing to the economy and the society based on knowledge is created, assumes and trains changes of paradigm in all areas, for instance: in administration through e-government, $e$-administration systems, in business through on-line commerce, in education through distance education, in culture through multimedia centers and virtual libraries and even in the actual manner of working with support systems for work at distance.

The generalization of the implementation and use of these types of systems for the entire public administration will entrain qualitative substance changes of the external audit approach.

The proposed project's objective is performing of advanced researches in online audit models and architectures field, finished in practical plan with the elaboration of an auditing model in this new approach, of the financial - accounting situations of a public institution financed from the local budget

In Romania, The National Electronic System (NES) through its $e$ - government and $e-$ administration components, is the implementation support for the online audit of the data collections delivered by the public institutions.

The National Electronic System (NES) was established as an information system of public use, with the objective of ensuring access to public information and public services offered to physical and juridical persons, by Law no. 161 from 19th of April 2003 regarding some measures for ensuring transparency in exercising public primacies, public functions and in the business environment, preventing and punishing corruption (Title II).

The National Electronic System is a unitary ensemble which contains the e-government and e-administration subsystems. The two components are not disjunctive, sharing resources and owning both a legislative and instrumental common and consistent frame for implementation and operations NES, as well as a common infrastructure for use. 
These priorities lead to changes in the content and manner of the auditing activity of the public institutions and of the electronic services provided by them, through the impact and effects generated both in the restructure of the audited field (informational/information systems reengineering), as well as in the audit approach (auditing architectures reengineering, methodological and procedural frame reengineering changing the auditing manner).

Internationally, the most relevant conclusions referring to e- government and the connected systems (e- systems) implementation stage, were provided by a study initiated during the last part of the British presidency of EU with the participation of some representative public and academic institutions, having as starting point the fact that the period $2004-2005$ highlighted a phenomenon of revision of the agenda regarding this field, phenomenon that could be seen at multinational scale. The main conclusion of the study is that we assist at a movement of paradigm in matter of e government: we assist at a series of emergent processes of change based on information technology and communication. We appreciate that the evolution highlighted in the study reflects a natural step from the approaches controlled by the specific infrastructures of information technology and communication (ITC) to a superior level, that of applications and systems.

At the Supreme Audit Institutions level, workgroups were formed with the objective of elaborating and promoting of a standardized work frame in order to turn to good account the benefits offered by the e-government/e-administration systems, by using the data deposit in the audit process. In this context, the online audit will be extended as well as development area and as instrumental support of auditing which will be mostly based on information and communication technologies.

At INTOSAI and EUROSAI level, specialized periodical evaluations regarding the stage and trends distinguished internationally in the IT audit field took place inside specialized workgroups. The new approaches enforced by the expansion of the e-government / $e$ administration systems.

The development of the informational society, characterized by integration and automation of processes and controls, by increased security in system functioning, but, on the other hand, by increased dependency on these systems, together with growing requirements of correct and operative information creates the need of a new approach upon audit procedures and architectures, specially for large scale socio-economic systems, like the systems in the Finance area and the connected areas or like the so called $e$-systems, which cover the technical and social areas (egovernment, e-commerce, e-learning, e-health and so on). Auditing these systems will be imperious necessary under the condition of the expansion of delivering and using the electronic systems, which assumes ensuring the compliance with the international standards in the field, with the aim of providing electronic services of the best quality to the citizens, administration and business environment and ensuring compatibility with European administrations.

Also, it must be bear in mind the fact that crossing to the society based on knowledge assumes a significant amplification of the importance of external audit engagements through expansion of the audit on all administration fields and on all types of electronic services, whose number is continuously growing.

In the last part of the British presidency of the EU, a study has been initiated with the participation of some representative public and academic institutions, having as starting point the fact that the 2004-2005 periods has relieved a phenomenon of agenda reviewing in the $e$ government field, visible multinational.

Critical analysis of the "as is" phase in the e-government field has been accomplished from the following perspectives:

1) A first perspective over e-government through country framework: the study includes a critical analysis of the "country framework' approach, with run-downs on the natural coordinates of the nationality, respectively the environment (physical, social and economic) and the infrastructures (market related, political, legislative etc.) 
2) A second perspective over e-government is provided through the public services approach, with run-down of some services important for the economy and the society which demonstrates certain progress elements regarding e-government (education, health, taxes etc.), including also technological aspects as well as benefits registered by the quoted services.

3) The third perspective examined might be defined through the approach based on common frameworks (like, for example, a common framework of interoperability; similarly, also common frameworks for functional processes and capabilities must be allowed for); this part of the study includes a number of central issues for the research and development or normalizing activities in the field of technology information governing (for example, system integration and security, to quote only two of these)

4) The study replenishes the review of these approaches with a suite of case studies selected in order to provide a bird's eye view over the level reached by the UE 25 space, as well as by other concurrent spaces.

The main conclusion of the study is that we assist at a displacement of paradigm in terms of e-government: we assist a number of resultant processes of change based on information technology and communication (ITC). We estimate that the development demonstrated in the study reflects a natural lunge, from the approach guided by the specific infrastructures of information technology ad communication (ITC) towards a higher level, that of systems and applications.

Of a real interest are also the characteristic memoirs of this evolution, well pointed out in the content of the study, out of which we will apprehend;

- $\quad$ focus on the reformation impact that e-government has over the public services;

- the development of the e-government concept towards a new concept, that of t-government, which can be defined at a first approach as "using information technology and communication (ITC) to ensures the transformation of the way government works in a client oriented manner". Related to this new $\boldsymbol{t}$-government new concept, three essential principles are defined:

o transformation: as a fundamental modification (much more than passing to on-line IT services);

- guided by the business and allowable by ITC: with the inherent requirement of a deep reengineering;

- benefits: for the citizen, business man, public services staff.

One of the central objectives of The $2^{\text {nd }}$ International Seminar on IT Audit meeting organized by CNAO (Chinese National Audit Office) in Nanjing in September 2004, with the participation of several INTOSAI member countries, was an appraisal of the status and most relevant trends in the IT audit field, as demonstrated globally. The workshop was oriented on two central subjects, regarding two fields which will revolutionize the audit field: electronic government (e-government), through providing an infrastructure for the connected systems and online audit, through substantial changes on the traditional approach of the audit. The workshop sub served at processing a clear and precise view over the status of approaches in these fields, globally. During the workshop, several countries have participated with works and papers: Brazil, Bhutan, Canada, People's Republic of China, Hong Kong, India, Japan, Great Britain, Macao, Norway, The Netherlands, Pakistan, Poland, Romania, Russian, Sweden and Hungary.

\section{Current status and progress as resulted from the Workshop's papers}

The papers presented during the workshop have shown the special interest in adopting a new approach based on modern audit techniques, facilitated by upgrading to electronic governing (online audit, e-audit). Included in the reference bibliography you may find the most representative papers presented during the workshop. 
The central issue of IT audit in general and on-line audit in particular as reported by the workshop participants is creating a framework to provide complex and complete data collections, applications, high level information technology tools, capable of facilitating access to the audited entities data, under information protection, security and integrity as well as to comply with legal requirements, executive and controlling, for creating the context required by audit engagements. Under the circumstances of the development of e-government platforms, proper infrastructures will be created, infrastructures required for developing systems that will allow globalizing information exchange, promoting IT applications, standardization of procedures, proper access to information under security conditions.

Designing and developing an audit management system assumes, besides the above presented infrastructure, the existence of a strategy at the supreme audit institution through which activities regarding executive management, human resources management, audit management are planned, developed and followed up.

Implementing computer based or computer assisted audit is an all-important stage, during which the following could be automated completely or partially: project management, data gathering, statistics compiling, sampling procedures elaborating, assessing and testing, work papers completing, audit report compiling and analyzing. Audit quality is critically influenced by a number of factors like: audit standardization, database quality, application interoperability, auditors training etc.

Starting from these base viewpoints, the papers presented during the workshop have detailed relevant aspects coming from own experience, have presented special accomplishments which could be classified as reference projects for other audit institutions (China: Golden Audit Project (GAP-I), Canada: GOL - Government On-Line ), have announced difficulties in implementing complex systems which demanded a change in the initial approach, have developed key points (IT audit standards, IT security, unifying the codes, application interoperability) and have relieved the trend of generalizing the new audit methods.

During the workshop, the Romanian delegation of the Court of Audit has presented the context, approaches and development perspectives of IT audit in Romania together with two case studies on audit through databases, as a way of on-line audit: audit of the recordings performed by the custom-house and audit of the VAT refunding.

Romania, like most of the participant countries, is now facing a great variety of platforms and applications, containing technologies from different generations; therefore, on-line audit approach is based on heterogeneous architectures, in which very few databases can be accessed online. Under these circumstances, a realistic solution regarding performing on-line audit is building up software components dedicated to specific, isolated applications, designed in a way that allows future integration in complex systems, intended in perspective of e-government strategy in Romania. We mention that this strategy is focused on building up the National Electronic System (NES), aimed to integrate public institution databases and to implement specific techniques, methods and procedures of communication and processing, based on a common interoperability framework and superior, from the qualitative point of view.

Developing the information society, defined by integration and automation of processes and controls, high security in system functioning and dependence on them, together with growing requirements of correct and efficient informing create the need of new approaches in audit procedures and architectures, specially for large-scale socio-economic systems, like the systems in the financial area and connected areas, the so-called e-systems.

In this context, the main issue for the supreme external audit institution - Romanian Court of Audit - is redesigning the audit architectures and focusing its capacity to identify the most adequate solution to optimize the audit flow, the methods and techniques used, in accordance to the scale of the audited systems. 
The approaches presented by the supreme audit institutions across the world have proved the unanimous and consequent orientation towards electronic governing, relieving the benefits provided by this, for the users as well as for the external auditors.

In Romania, the e-government field has recently been the scope of an audit performed by The Romanian Court of Audit, audit which was a premiere in the field and provided opinions of a great importance regarding mainly management involvement at governmental level in all stages of the system's life cycle based on a strategy which is part of the Romanian Government Strategy for developing the information technology sector. This strategy assumes a coherent e-government program, a coherent policy of financing the related programs and projects, an administrative structure with clear responsibilities regarding coordination of the e-government system, with clear objectives statement.

The audit had as objectives: technical assessment of the system, determining the level of using the information technology and communication (ITC) in providing electronic services to physical and juridical entities, as well as the way of involving in a number of mandatory activities as part of the European action plan, in order to allow Romania to participate at the European governing and administration electronic systems.

\section{Institutional and legislative context}

The upgrade to e-government and e-administration in Romania has been marked by a number of imperative actions:

- introducing a work group - The Group for Promoting Information Technology in Romania (Government Decision no.271/22 February 2001), whose main objective is creating solid premises for implementing the information society in Romania;

- elaborating and approving The Government Strategy regarding implementing information systems in the public administration sector (Government Decision no. 1007/4 October 2001);

- approving The national strategy for promoting a new economy and implementing the information society (Government Decision no. 1440/12December 2002) which underlines the fact that upgrading to the Information Society is one of the strategic objectives of the Romanian Government for the 2001 - 2004 periods and one of the conditions for preadherence to the European Union.

- founding the National Electronic System (NES), as a information system of public utility, aimed to ensure access to public information and to provide public services to physical and juridical entities.(Title II - Law no 161/19 April 2003, regarding transparency in managing information and public services through electronic means).

- founding the National Information Centre of Ministry of Administration and Internal Affairs, CIN-MAI (Government Decision no. 1362/26 August 2004, regarding the National Information Centre of Ministry of Administration and Internal Affairs and implementing the $e$-administration system), creates the legislative framework for implementing the $e$ administration system.

The legislative framework was completed with a number of rules and regulations regarding: electronic signature in on-line auctions, cashing in the local taxes through electronic means, electronic assignment and allocation of international land conveyance of material, the procedure for approving distance payment instruments on Internet-banking, home-banking or mobile-banking type of applications, actions for performing information exchange in the technical standards and regulations field between Romania and the European Union state members, individual protection regarding personal data processing and free movement at these data. 
Along with Romania's adherence to EU, the use of information technology and communications with the aim of redefining the relationship between citizens and public administration, between public institutions, between public institutions and their employees in terms of facilitating everybody's access to public services and information has become a requirement. This is translated in Romania's alignment to the European Union Community programs created with the objective of extending the electronic services (e-services) at a trans-European dimension (IDA e-TEN, i2010). The programs promote public concern services which provide to any citizen business entity or administration - the opportunity of trading on the benefits of the information society.

Implementing services like e-government, e-administration should stimulate the use of new technologies, the development of information systems dedicated to public administration backoffice being a priority for coherent implementation of systems for the whole public sector and for restyling the public administration. In this context, beside the investment in technology, also restructuring of management is required, which will be performed consulting the "as-is" status of using IT\&C in public administration, as well as the usage level of electronic services dedicated to citizens. Based on these facts, the next implementation stages of this new concept in Romania should be clearly defined. Revising a new strategy of expanding the deployment of information systems in public administration and crossing to electronic administration is more important as at E.U. level, one of the priorities is developing such a strategy for the member states and correlating it at European level through $i 2010$ initiative for creating a unique European space.

The Ministry of Communications and Information Technology, the special institution of public administration in the information technology and communication field, having the assignment to create the Government's policy for this field, has elaborated a number of strategies like: Government of Romania - Strategy of stimulating and sustaining the communications sector development during the period 2002-2012, Economy based on knowledge, Government of Romania - Strategy for developing the information technology sector, National strategy for export, Strategy of durable development of Romania ORIZONT - 2025.

At the present moment, the project Economy based on knowledge is under development in Romania. The project aims to more sectors and financed by The World Bank, which reunites under the governance of The Ministry of Communications and Information Technology, The Ministry of Education and Research, The Ministry of Interior and Administration Reform, Ministry of Culture and Cults and The National Agency for Small and Middle Sized Enterprises and Cooperatives

The main goal of the project is developing and promoting the e-government services, modernizing the educational and training process at rural and small towns level (with less than 30.000 people), as well as promoting electronic trade and adopting innovative solutions in the local business environment. The project also integrates a cultural component by connecting the libraries at the rural/urban level to the digital culture national network. These virtual networks will connect the major social, economical and educational institutions from the local communities: the school, the city hall, the library and will ensure a public point of access to information, national and global information and trading networks. The target group of these projects consists of the communities disadvantaged from the access to knowledge point of view.

In conceiving and structuring a strategy of building up the economy based on knowledge, the information technology and communication field is the major resource and the inceptive condition which provides the sine qua non framework of transforming the knowledge in raw material, stock, products and factors for manufacturing essential to economy and for restructuring the economic processes inside of which initiating, selling, purchasing, storing, developing and protection of knowledge become predominant and decisively determine driving profit, durable development and long term economic sustainability. Because of this, the development of the strategy for economy based on knowledge depends on the status of the ITC sector development and on the perspectives which come out of the action courses and associated sector programs. 
The Ministry of Communications and Information Technology policy for ensuring integrity and security of the public electronic communication networks follows three main goals: preventing actions aimed against information systems and communication networks, reducing vulnerability at these attacks as well as minimizing the damages and the recovery time. This policy ensures the framework for implementing controls for e-government participants, as well as public informing and acknowledgement, creating a national culture regarding security and, last but not least, training the users.

An efficient action initiated by MCTI which is about to be implemented is promoting audit of information systems and communication networks security, which should provide detailed information about elements involved in information security, evaluate, at enterprise level, the vulnerability and existing threats regarding security issues, assess and recommend the optimum security infrastructure in the ITC field.

Assurance of security and electronic fraud restriction is realized by creating and implementing the portals www.efrauda.ro (a portal through which the frauds from the information society field are reported and all the concerned authorities are alerted and www.ceris.ro (centre of expertise and answer to security issues which ensures access to information regarding system and network security providing assistance to public institutions on key points like increasing the security level of information systems and communication networks associated).

Ensuring accessibility to public services over the Internet and web technologies requires introducing and extending of technologies like smart-cards, digital signature, electronic certificates, electronic forms etc. This is a requirement for a safe and modern infrastructure which will provide the support for performing electronic transactions.

\section{The e-administration component of The National Electronic System}

Implementing information systems for services provided by local public administration having as recipients the citizens and enterprises is at an early stage: pilot projects have been complemented by MCTI and other governmental institutions. The following are operative: services of providing information over the Internet through public administration web sites, a number of forms and services in electronic format are available (e-licitatie, e-tax, e-banking, transport license, e-job etc.).

A number of territorial communication networks have been implemented by the county administration or other local authorities: towns, cities, villages etc. A number of initiatives regarding implementing procedures for coordinating and cooperating between counties have been taken into consideration with the goal of ensuring the homogeneity of services at national level and interactive change of information. At the present moment, these solutions are heterogeneous at national level.

Establishing, at national level, the policies which contribute to adopting standards and recommendations in the information technology field, regarding efficiency and security of electronic administration systems, regarding interconnectivity and interoperability of electronic administration systems and connected databases is of great importance. This can be accomplished by formulating some legislative initiatives, by promoting a certain level of quality for the administrative services provided to the citizens, by participating in workgroups etc.

The efficiency of implementation and use of the National Electronic System is materialized in a number of effects, starting from the advantages offered to the Romanian citizens by having access to quality telecommunications at a low cost and to broad band services, until the implementation of a more efficient administration, with increased speed of responding at citizens' requests.

The banking and financial activities reflect the best the efficiency of implementation and use of the National Electronic System through increasing the rotating speed of money capital, 
shallow collecting of debits from citizens, effective economic and commercial trading between enterprises, reducing cost of issuing and maintaining cash on the market, increasing flexibility and security of payment systems.

The audit of Public Services performed for Local Public Finance has rendered the existence of operative back-office systems (ATLAS, ASSERT, IMTAX2000, Local Tax, SIMTAX and others) which provide information for the online electronic payment services.

The portal for electronic payment of taxes is operative in more than 60 towns and cities. The tax payers have to register as users of the electronic Internet payment system at The Public Service for Local Public Finance headquarters, receiving a free, confidential access code (password). Using the password together with personal identification data allows access to information regarding the goods held, the amounts to pay and the payments already processed in account of these goods. The tax payer has to have an agreement with one of the bank institutions providing $e$ banking services, under the form of a subscription to electronic Internet payment services.

The operations of inquiring and tax paying can be performed at any moment of the day, without any presence to town hall or bank being necessary. An evidence of electronic payment is issued to the tax payer under the form of a confirmation letter electronically signed through a numerical certificate which contains the identification of the tax payer as registered in the financial administration databases, the identification of the payment beneficiary, transaction numbers for further information over debits, processed payments and detailed operations.

The system for public procurement performed by electronic means, including payments by electronic payment systems, e-licitatie has been deployed on March $4^{\text {th }}, 2002$, is unique in Europe as size and scope and has been nominated at European level as an example of good practice in the e-government field (Como, Italy, 2003). By using this system, public institutions in Romania have the possibility of goods and services procurement through electronic means, which lowered the procurement costs by $22 \%$. The system is used in approximately 1000 public institutions and 3300 private enterprises. The number of goods purchased online has increased significantly.

The Government has to answer at new challenges with an increased efficiency for the provided services, has to go beyond the borders of vertical structures and to allow horizontal interconnectivity. Availability of online data at a large scale facilitate the collaboration of institutions through electronic means, the proposal of packages of integrated services, the development of efficient ways of communication the sharing of data.

Creating a standard framework of interoperability and a coherent system architecture will ensure the following benefits: reducing total costs by reusing and avoiding duplicate applications and systems, reducing project implementation time, improving project management and implementation methods, concluding on the migration policies for the existent heterogeneous systems.

Restyling the Government's and public institutions' activity assumes, also, an improvement of internal management efficiency, reducing administrative costs by using electronic means in communicating and relating to their employees - the public officers.

The most significant benefits provided by the e-government implementation are:

- reducing public expenses, fighting bureaucracy and corruption at the public institutions level;

- increasing the level of transparency of the way of using and managing the public funds;

- improving access to information and public services in compliance with the rules and regulations regarding personal data protection and free access to public information;

- eliminating the direct contact between the public officer and the citizen/private enterprise;

- providing quality information and public services through electronic means;

- strengthening the managing capacity of public institutions for fulfilling their role ad objectives and providing public information and services in a transparent manner; 
- promoting collaboration between public institutions for providing public services through electronic means;

- redefining the relationship between citizens/business environment and the public administration, by facilitating their access to public information and services, through information technology;

- promoting the use of Internet and high level technologies in the public institutions.

The rapid development of information technology in the last decade has created new directions of business development through electronic commerce, activity which involves manufacturing, advertising, sales and logistics, as well as a multitude of ways of collaborating between entities. Through its development, electronic commerce has contributed to communication globalization and mobile communication development.

The changes in approaching the Information Society by facing towards a Society based on knowledge, which assumes transforming the whole economy in a digital economy, involves major changes in approaching external audit, in what regards audit management and auditor's role as well as architecturally, methodologically and procedurally.

These changes require a new treatment in the audit field and the need of creating a new audit framework for the whole lifecycle, considering the qualitative change in the field and objectives of audit: audit will target the management and delivery of electronic services which assume electronic documents workflows and associated specific treatment procedures. This is the reason why most of classic audit procedures will be replaced with procedure that will ensure audit of the digital context which is presently expanding.

In Romania, the premises have been created by introducing the National Electronic System (NES), as an informatics system of public use with the purpose of ensuring access to public information and providing public services to physical/juridical entities (Title II from Law 161/19 April 2003, regarding transparency in management of public information and services through electronic means).

Reengineering audit's lifecycle imposes the requirement of reengineering the audit architectures and the classic methodological and procedural framework with the aim of aligning it to the new context and of creating a new audit template. Classic audit will change its content and approach and will be based mainly on information technology and communications by adopting more advanced methods: online audit, continuous audit, e-audit.

The public institutions will coexist in a globally integrated and interoperable IT environment which will ensure extended access to public information and will provide IT public services to physical/juridical entities.

The auditor will have to be prepared for working in virtual audit teams, for adopting a new way of working: distance audit, orientation to electronic documents audit, using computer based or computer assisted tools and support.

The new context by crossing to the society based on knowledge will induct major changes in what regards information and system security, personal data protection, taking into consideration access to databases of sensitive information, exposed to external attacks from the Internet. Ensuring system continuity, change and development management will have to be built upon an adequate methodological and procedural framework. The aspects which involve major risks in implementing this new audit model - bringing up to date the rules and regulations framework, creating a framework of interoperability of public administration institutions from Romania and integrating it in the European public administration system, training the auditors for these steps, redesigning audit management, insuring audit quality, insuring audit support tools and methodologies - must be taken into consideration and treated with maximum serious.

All these transformations which will induct deep qualitative changes in external audit approach have to be supported by a new strategy of the external audit institution, which will create the official framework for implementing and progressing towards a new paradigm of 
external audit. Taking into consideration that one of the major risks of auditing such a system is the novelty of the system itself, it has been relieved the need of performing further studies with the aim of elaborating a set of supportive tools and methodologies, appropriate for assessing the implementation and use of information technology and communication (ITC) with the purpose of crossing to electronic government as well as formulating best practices specific to this field.

Through the governmental portal (e-government.ro), information systems from the public administration could be connected to provide integrated services.

\section{Bibliography}

1. A Global Check-Up: Diagnosing the Health of Today's Organizations, DeAnne M. Aguirre, Lloyd W Howell, Gary L. Neilson, www.boozallen.com

2. Beyond e-Government. The world's most successful technology-enabled Transformations, Booz Allen Hamilton, www.boozallen.com

3. How to improve project management and programme management quality, Dr. Martina Huemann PROJEKTMANAGEMENT GROUP, Vienna University for Economics and Business Administration, Franz Klein-Gasse 1, A-1190 Vienna, Austria

4. Systematic Planning and Evaluation of the Project Management Effort, Morten Fangel, Managing Director \& Chief Consultant, Fangel Consultants Ltd, Denmark

5. Audit financiar 2005 - Standarde. Codul privind conduita etica si profesionala, Camera Auditorilor din România, 2005

6. IS Standards, Guidelines and Procedures for Auditing and Control Professionals, editia februarie 2005, www.isaca.org

7. COBIT Control Objectives, Editia 4.0,www.isaca.org

8. Towards Online Auditing. The database environment, Claudia Ionescu, Stefan Popa, The $2^{\text {nd }}$ International Seminar on IT Audit, Nanjing, 2004

9. Audit în medii informatizate, Stefan POPA, Claudia IONESCU, Editura EdExpert, Bucuresti (2005)

10. Auditul sistemelor informatice, Stefan POPA, Claudia IONESCU, Tribuna economica, revista Controlul Economic si Financiar Nr.9/2005, Bucuresti

11. Tehnologia informatiei în auditul extern, Claudia IONESCU, Stefan POPA, Tribuna economica, revista Controlul Economic si Financiar Nr.3/2005, Bucuresti

12. Business Risk Assesment, David Mc Namee, The Institute of Internal Auditors, USA, 1998, www.theiia.org

13. Applying COSO's Enterprise Risk Management - Integrated Framework, Executive summary, The Institute of Internal Auditors, September, 2004

14. The Pentana Audit Work System v4 - A Functional Overview, www.pentana.com

15. "Perspectives on the information exchange", into IT, no. 39, www.intosai.org

16. "Best practice - Why IT Projects Fail", www.nao.gov.uk/intosai/edp 